\title{
An Experimental Investigation of ZnO Nanoparticles Effect on the Acrylic Coatings
}

\author{
GHAZALEH KHALAJI', MOSTAFA MALEKI² and ASHKAN MEMAND1* \\ 'Department of Petroleum Engineering, Faculty of Engineering, University of Garmsar, Garmsar, Iran. \\ 2Department of Mechanical Engineering, Dezful Branch, Islamic Azad University, Dezful, Iran. \\ *Corresponding athor E-mail: memaashkan2015@gmail.com
}

http://dx.doi.org/10.13005/ojc/350125

Received: October 20, 2018; Accepted: December 01, 2018)

\begin{abstract}
In this study, the properties of acrylic coatings based on paraloid B-72 were improved by adding of $\mathrm{ZnO}$ nanoparticles. Steel plates were used as substrate. $\mathrm{ZnO}$ nanoparticles was analyzed by transmission electron microscopy (TEM). The effect of adding $\mathrm{ZnO}$ nanoparticles on the the coatings was investigated using contact angle measurements. The modified coating with a $\mathrm{ZnO}$ nanoparticles showed more efficient performance than the net coating after 30 days UV radiation. Generally, this work confirm the positive effect of adding $\mathrm{ZnO}$ nanoparticles on acrylic coatings.
\end{abstract}

Keywords: ZnO nanoparticles, Acrylic coatings, Color change.

\section{INTRODUCTION}

Acrylic/Meth acrylic polymers are widely used in many industries; for example, as a mediator in formulation of paints and surface coverings, as well as a base for glues. One of the most important and special applications of them is in art (artistic) paints and protection of cultural heritage ${ }^{1}$.Protective operations by acrylic resins are reported for wood, paper, mosaic, pigment, enameled (glazed) vessels, amber (succinum), fossils, ceramics, glass, stones and metals ${ }^{2,3}$. Good adhesive characteristics and impermeability (waterproof being) of acrylic resins resulted in their use in the above- mentioned applications, where at the same time, enough environmental stability (consistency) is also regarded, especially in cases where the resins are used as protective coatings of old buildings and art (artistic) works which are exposed on external (outside) environment. Long-term efficiency (output) of protective coverings (coatings) is fundamentally influenced by direct effect of sunlight in stimulation of oxidation reactions. This effect might be intensified due to temperature, humidity and especially, in presence of air pollutants. The complexity of natural aging of materials can be made possible in the laboratory and just by use of a facilitated approach (procedure) through simulation with short-term experiments. The studies on prediction of materials' life range (long life) are usually performed through the accelerated aging experiments including temperature and/ or light ${ }^{4,5}$.

This is an Open Access article licensed under a Creative Commons license: Attribution 4.0 International (CC- BY). Published by Oriental Scientific Publishing Company @ 2018 
The light (photo) source which is used for such goals, should have high output potential near sunlight spectrum, especially within the domain of UV (ultra-violet). Radiations with shorter wavelengths should be omitted since the researches (investigations) showed that they can result in some reactions which don't practically occur (happen) in natural environment ${ }^{6,7}$.

By increasing attention paid to the materials with nano dimensions, Various nano particles are added to polymeric fields (grounds) until their different characteristics will be modified. Very small size of nano particles, i.e., less than 100 nanometer $(\mathrm{nm})$, causes their invisibility after injection into polymeric ground. Therefore, it leaves no undesired effect on photo (optic) characteristics of polymers. In some cases, even increased transpiration is also reported. Very large active surface of nano particles caused they be appropriate to use in various superficial operations. Research (Investigations) showed that adding $\mathrm{ZnO}$ nanoparticles caused significant change in the behavior of coating (covering) and improvement (enhancement) of mechanical, chemical and optic characteristics of polymeric ground ${ }^{8,9}$. In other studies, adding nanoparticles including zinc and are examined as anti-corrosion as well as the modifiers of mechanical characteristics for epoxy coatings ${ }^{10}$ and sel-gel coatings of silane base ${ }^{11}$. These exclusive characteristics of nanoparticles caused to use them in coating industries in order to improve physical, chemical and mechanical behaviors of organic coatings. In this research, paraloid resin B72 was used as the main (primary) coating. Following it, nano composite coating was produced by use of adding $\mathrm{ZnO}$ nanoparticles. The goal of this research is to examine the effect of adding $\mathrm{ZnO}$ nanoparticles on protective characteristics of acrylic coatings (coverings). Nano composite coating was obtained through adding two different silane factors to paraloid resin B72, and was exerted on steel background. Then, protective characteristics of these coatings are examined in terms of humidity (permeability) and resistance against aeration.

\section{MATERIAL AND METHODS}

Zinc nitrate with chemical formula of $\mathrm{Zn}\left(\mathrm{NO}_{3}\right)_{2} \cdot 6 \mathrm{H}_{2} \mathrm{O}$, Methacryloxy propyktrine thoxy silane with chemical formula of $\mathrm{CH}_{2}=\mathrm{C}\left(\mathrm{CH}_{3}\right) \mathrm{COO}\left(\mathrm{CH}_{2}\right)_{3}$ $\mathrm{Si}\left(\mathrm{OCH}_{3}\right)_{3}$ and acetone with chemical formula of
$\mathrm{C}_{3} \mathrm{H}_{6} \mathrm{O}$ all were purchased from Merck company and were used in this research without any purification. paraloid resin B72, dual (binary) copolymer from Methyl Acrylate (MA) and Ethyl Methacrylate (EMA) with approximate molar ratio of 5:2 were purchased from Lascaux Restauro company. Steel sheet Ck60 was used as sublayer. This sheet was cut into smaller pieces with dimensions of $36 \mathrm{~cm}^{2}$. In order to obtain (achieve) mirror surfaces, steel sheets were initially grindstoned (sandpapered) using sic grinder papers. Then, they were polished by means of suspension including alumina nanoparticles. Before exerting polymeric coatings, the samples were skimmed in the acetone using ultrasonic shaker.

In this research, three coatings with different compounds (compositions) were exerted on steel sample: coating $A$ includes paraloid resin B-72 without adding silane compounds, coating $B$ includes paraloid resin B72 which is obtained by adding 3 percent volume of Tetra ethoxy silane, and coating $\mathrm{C}$ which is resulted from adding 3 percent volume of Methacyloxy propyl trimethoxy silane to coating $\mathrm{B}$. The coatings were exerted in steel background using Film-killer system. Then, the samples were exposed on fresh air for 48 hours. Then they were transferred into the oven and thermal operation was performed at temperature of $135^{\circ} \mathrm{C}$ for two hour. In order to study the quality of distribution approach of $\mathrm{ZnO}$ particles on polymeric background, their shape and size, Transmission Electron Microscope (TEM) were used. To determine the thickness of coatings, TEM images of crosssections of the samples were examined. Topography and coarseness of the surfaces of coatings were also studied using atomic force Microscope. In order to determine hydrophilicity and hydro phobicity of coatings resulted from contact angle system, Model KRU ss G10, made in Germany, the distilled water was used as the test liquid. Contact angle is obtained using drop profile analysis technique under controlled conditions of humidity and environment (ambient) temperature. To ensure the repeatability of results, all experiments were repeated three times on the samples and the mean numbers were reported.

The effect of adding $\mathrm{ZnO}$ nanoparticles to paraloid resin $B 72$ on changes in their colors during UV test was examined using color measurement system. In this test, the samples were put into UV 
compartment [with dimensions of $42 \times 49 \times 47 \mathrm{~cm}$ ) for 1000 hours according to ASTM 4587 standard. Color indices/ parameters $\left(L^{*}, a^{*}, b^{*}\right)$ and total changes in color were measured using CIE 1976 formula (equation 1) at contact angle of 45-degree and the observation angle of 10-degree.

\section{RESULTS AND DISCUSSION}

In Fig. 1, Transmission Electron Microscopic image of $\mathrm{ZnO}$ nanoparticles is shown in sample $\mathrm{B}$. It is observed that the particles have relatively globular shapes and their mean size is about 10-20nm.

The results obtained from contact angle

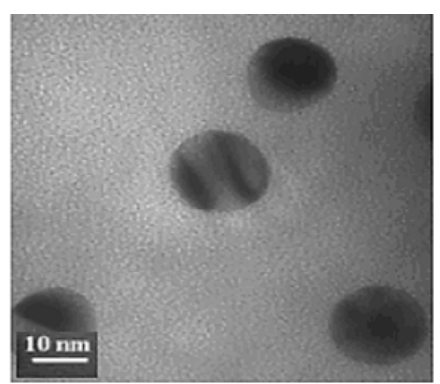

Fig. 1. TEM image of $\mathrm{ZnO}$ nanoparticles

measurement test for pure acrylic coating as well as the coating containing $\mathrm{ZnO}$ particles inferred (deducted) that coating $B$ has the highest (greatest) coarseness among the coatings.

Additionally, there is no significant difference between the coarseness of coatings $A$ and $C$. These results are gathered by the findings of Mohammad in Table 1. The images related to the drops are presented in Fig. 2. Data resulted (obtained) from the permeability test is used to predict the protective characteristics of coatings against water and vapor (steam). The results represent that the contact angle is increased in both samples containing $\mathrm{ZnO}$ particles but this increase is significant in respect of sample $B$. Regarding the bigger the contact angle is, the more hydrophobia the coating will be; and the smaller the contact angle is, the more hydrophile the coating will be; and by referring to the available results in Table 1, it can be concluded that adding $\mathrm{ZnO}$ nanoparticles to the polymeric background causes to improve the hydrophobicity of acrylic coating. Iron alloys are strongly sensitive (vulnerable) against the humidity and develop corrosion in presence of it.

Finally, the coating which is more
Table 1: Results obtained from permeability test for different coatings at the temperature of $25^{\circ} \mathrm{C}$ and the humidity of $40 \%$

\begin{tabular}{cc}
\hline Name of coating & Contact angle (degree) \\
\hline Coating A & 76.1 \\
Coating B & 93.7 \\
Coating C & 84.2 \\
\hline
\end{tabular}

hydrophobia, absorbs less humidity from the environment.

This will be effective on decrease in its corrosion rate ${ }^{12}$. The above-mentioned results have conformity with the findings when the coarseness of surface increases, the desired (given) coating will become more hydrophobia. When the contact angle is between 0 and 90 , the common space between liquid and solid (surface) is high and the liquid wets the surface well. This state occurs for the surfaces with low coarseness ${ }^{13}$.

In cases where the contact angle is between 90 and $180^{\circ}$, the liquid cannot easily permeate into the coarsenesses of the surface which have been filled by air. Consequently, the common surface between the liquid and gas will not be continuous (indiscrete). Instead of it, we will have liquid-gas and liquid-solid common surfaces. This case (state) occurs for the surfaces with high coarseness.

By non-armed eyes, it can be observed that

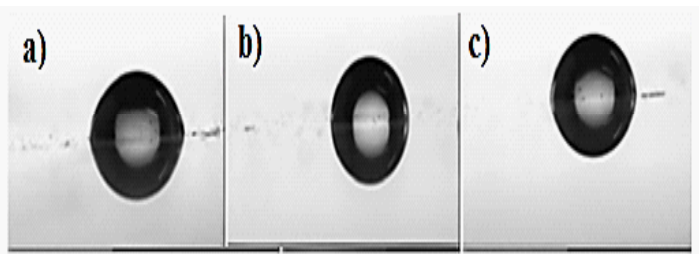

Fig. 2. Images related to the drops obtained from permeability test for (a)coating A, (b) coating B and(c) coating C.

no significant change in coating $B$ has been occurred after UV (ultra-violet) radiation, while samples $A$ and $C$ have somewhat changed their colors. Generally, during aeration of polymeric materials, the least electron stimulation energy is related to the transfer (transmission) of $\pi \rightarrow \pi *$ of $\mathrm{C}=\mathrm{C}$ and $\mathrm{C}=\mathrm{O}$ bands, These factors are strongly absorbed in ultra-violet (UV) are a and are well-known as color-makers which are the main (primary) elements which constitute color compounds. Most organic bands don't absorb UV (ultra-violet) light in frequencies higher than $280 \mathrm{~nm}$. Therefore, they are not directly 
destroyed (deteriorated) by sunlight. But low values of impurity (peroxide, ketone) in polymeric materials can absorb the light and form free radicals which finally results in photo (optic) destruction of the coating ${ }^{14}$.

The stability of coatings in terms of resistance against UV radiation is examined using changes in their colors through measuring the color during the radiation in UV compartment compared to pre-test state. Data of color indices (parameters), i.e., $L^{*}$ (lightness/luminescence), $\mathrm{a}^{*}$ (color distinction), $\mathrm{b}^{*}$ (yellowness) and $\Delta \mathrm{E}$ (total color change) for different coatings before and after putting into UV compartment are gathered in table 2. The lightness (luminescence) index $[\mathrm{L}]$ ranges between 0 to 100; if this number is near to zero, it represents the darkness of the coating, and if this number is near to 100 , it represents the brightness of the coating. Referring to Table 2; after $1000 \mathrm{~h} \mathrm{UV}$ radiation, lightness (luminescence) index has been decreased in all three samples compared to the state before the radiation, which confirms more darkness of the coatings. This can essentially be attributed to the effect of light on the acceleration of reactions related to the organic materials decomposition and the breakage (split) of polymeric bounds. As observed in table 2, sample $B$ has the least value of total color change index $(\Delta \mathrm{E})$ among the samples which represents higher (greater) resistance of this coating against the color change by effect of (due to) UV radiation.

Table 2: Data of color indices (parameters) before and after UV radiation test for $\mathbf{3 0}$ days

\begin{tabular}{lcccc}
\hline Sample & $\mathrm{b}^{*}$ & $\mathrm{a}^{*}$ & $\mathrm{~L}^{*}$ & $\Delta \mathrm{E}$ \\
\hline Coating A before radiation & 0.28 & 4.15 & 78.16 & 0.39 \\
Coating A after radiation & 0.12 & 3.93 & 75.15 & \\
Coating B before radiation & 0.15 & 4.01 & 77.84 & 0.37 \\
Coating B after radiation & 0.14 & 3.89 & 76.02 & \\
Coating C before radiation & 0.20 & 4.02 & 77.91 & 0.53 \\
Coating C after radiation & 0.05 & 3.85 & 75.17 & \\
\hline
\end{tabular}

It seems that adding TEOS to polymeric background prevents the creation of more color change in the sample. But adding MPTMS to this coating in the second stage results in formation of heavy silicious chains and finally, these heavy linear polymers cause the yellowness and darkness of the sample.

\section{CONCLUSION}

Different coatings including different values of silane factors were prepared and their characteristics were studied in order to examine the effect of $\mathrm{ZnO}$ nanoparticles presence in polymeric background on their protective behavior against UV (ultra-violet) radiation as well as the permeability. Morphology images of the surfaces of coatings showed that a monotonic (homogenous) and defect-free coating including $\mathrm{ZnO}$ nanoparticles is formed on the steel background which confirms a good conformity between acrylic resin and $\mathrm{ZnO}$ nanoparticles. Data obtained from permeability test showed that the contact angle has been increased in both samples 1 containing $\mathrm{ZnO}$ particles.But this increase is significant in respect of sample $B$. The main reason for this can be searched in higher (more) coarseness of the surface of this coating compared to B72 paraloid-based coatings, a known (well-known) coating in repair operations using the modified $\mathrm{ZnO}$ nanoprticles of two other coatings. The results of samples' aging influenced by UV radiation indicated that the sample including TEOS displayed the least color change compared to other samples. In sum, the results obtained from this research show that the protective characteristics (in terms of permeability and color change) of the coating modified by $\mathrm{ZnO}$ nanoprticles has been improved compared to the pure acrylic coating which confirms the positive effect of adding $\mathrm{ZnO}$ nanoprticles to the polymeric background.

\section{ACKNOWLEDGMENT}

This research did not receive any specific grant from funding agencies in the public, commercial, or not-for-profit sectors.

\section{REFERENCES}

1. Oktay, B.; Toker, R.D.;, Kayaman-Apohan, N. Polym Bull., 2015, 72(11), 2831-2842.

2. Zhang, C.; Zhang, S.; Gao, P. Thin Solid Films., 2014, 570, 27-32.

3. Mahadik, S.A.; Vhatkara, R.S.; Mahadik, D.B.
Appl Surf Sci., 2013, 277, 67-72.

4. Davidson, k.; Moyer, B.; Ramanathan, k.; Preuss, A.; Pomper, B. JCT Coatings Tech., 2007, 56-61.

5. Ghorbani, H.R.; Molaeic, M. Prog. Org. Coat., 2017, 112, 187-190 
6. A. Panacek, A.; Kvitek, L.; Prucek, R.; Kolar, M.; Vecerova, R.; Pizurova, N. Journal. Phys. Chem., 2006, 110, 16248-16253.

7. Ghorbani, H.R. ; Alizadeh, V. ; Mehr, F.P. ; Jafarpourgolroudbary, H. ; Erfan, K. ; Yeganeh, S.S. Prog. Org. Coat., 2018, 123, 322-325.

8. Ghorbanic, H.R. Chem. Eng. Commun., 2015, 202(11), 1463-1467.

9. Liao, R.; Zuo, Z.; Guo, C. Appl Surf Sci., 2014, 317, 701-709.

10. Xie, L.; Tang, Z.; Jiang, L. Surf Coat Technol.,
2015, 281, 125-132.

11. Peng, P.; Ke, Q.; Zhou, G. J Colloid Interface Sci., 2013, 395, 326-328.

12. Ghorbani, H.R.; Orient. J. Chem., 2014, 30 (2), 803-806.

13. Sung, Y.H.; Kim, Y.D.; Choi, H. J. Appl Surf Sci., 2015, 349, 169-173.

14. Ghorbani, H.R.; Mehr F.P.; Pazoki, H.; Rahmani, B.M. Orient. J. Chem., 2015, 31(2), 1219-1221. 